\title{
Social environmental impacts on survey cooperation
}

\author{
MICK P. COUPER \& ROBERT M. GROVES
}

Survey Research Center, University of Michigan and Joint Program in Survey Methodology, 1218 Le Frak Hall, College Park, MD 20742, U.S.A.

\begin{abstract}
Social environmental influences on survey cooperation are explored using data from six national household surveys in the United States matched to 1990 decennial census data. Consistent with the past literature on prosocial behavior, cooperation rates in these six surveys are found to be lower in urban, densely populated, high crime rate areas. Measures of social cohesion show no evidence of influencing cooperation. The influence of the environmental variables is then observed after introducing statistical controls for household structure, race, age of household members, presence of children, and socioeconomic attributes of households. Over half of the measured influence of the environmental variables is explained by these household-level attributes. These findings have practical import for survey administrators and are informative for the construction of a theory of survey participation.
\end{abstract}

\section{Introduction}

Nonresponse threatens the value of the sample survey method for describing and understanding social phenomena. Nonresponse increases the cost of data collection through efforts to persuade those who are reluctant to participate, increasing sampling variance of survey statistics through diminished sample sizes, and increases the bias in survey statistics, as estimates of population parameters.

Two strains of literature address the problem of nonresponse, the first examining methods to increase response rates in surveys (for a review, see Groves, 1989), and the second focusing largely on attempts to reduce nonresponse error through the use of postsurvey adjustments (see Kalton, 1983). We believe that both reduction and adjustment approaches should be informed by a theory of survey participation. A full understanding of decisions to participate in surveys would guide the choice of procedures to keep nonresponse at acceptably low levels and would help in the allocation of resources for such efforts. Such a theory would also guide assumptions inherent in statistical adjustment of survey data.

We are currently working on the specification of such a mid-level theory of survey participation, focusing on face-to-face surveys (see Groves et al., 1992). Factors that may shape the decision to cooperate with or refuse a survey request include survey design features, the social environment, 
interviewer and household(er) characteristics and the householder-interviewer interaction at the time of contact (see Groves and Couper, 1995a). This paper focuses on only one set of factors, namely the role of the social context or environment in affecting cooperation. We do so because social environmental differences are the most ubiquitously observed in surveys, with consistent findings in the literature, and because we have data that allow us to control on the effects of household-level attributes while measuring environment differences.

\section{Social environmental factors in cooperation}

We believe the social context or environment of a sample household has important effects on the predisposition of members of that household to respond to a survey request. A variety of contextual factors are hypothesized to influence survey cooperation, including urbanicity, population density, crime rates, and a lack of social cohesion. We examine the separate and combined effects of these factors on cooperation.

One of the most consistently documented ecological correlates of survey cooperation is urbanicity (see Brehm, 1993; Goyder et al., 1992; House and Wolf, 1978; Smith, 1983; Steeh, 1981). Residents of small towns are found to cooperate at a higher level than those in large cities, while those in rural areas respond at an even higher rate. Effects have been found for a number of different measures of the urbanicity concept: old city versus.new, inner city versus suburb, large city versus small, urban versus rural, and so on. In all of these, the trend is clear: residents of inner-city areas of large metropolitan areas exhibit the lowest levels of cooperation, while those in rural areas have the highest. The urbanicity effect is observed in a widc varicty of countries. Consistent effects of urbanicity are also found in the literature on helping or prosocial behavior (see Levine et al., 1994; Steblay, 1987).

Although urbanicity is a common correlate of nonresponse, the finding, by itself, does little to explain why people in different size communities differ in their likelihood of cooperation with a survey request. We believe that many of the effects of urbanicity found in the literature may be explained in terms of greater population density, higher crime rates, and social disorganization, which are often associated with life in large urban areas.

A second contextual factor is population density, which is hypothesized to reduce cooperation through the experience of crowding. It is important to distinguish between density, a physical condition, and crowding, an experiential state associated with density. The former is a necessary antecedent rather than a sufficient condition for the experience of crowding (see Stokols, 1976). 
McCarthy and Saegert (1979) suggest that the perceptions of crowding are not related to density per se but rather to the experience of excessive social encounters in high density areas that lead to social overload. Social psychological theories of density and crowding (e.g., Baum and Valins, 1979; Tittle and Stafford, 1992) suggest that residents of densely populated urban environments face a greater volume and variety of contacts with strangers, most of which are impersonal and fleeting. The stress produced by such overstimulation leads to avoidance of contacts with strangers. This leads to less helping behavior and greater distrust of all except family and close friends (see Franck, 1980; Milgram, 1970; Wilson, 1985). Korte et al. (1975) found that differences in helping behavior between urban and rural dwellers disappeared when controlling for levels of stimulus input. This suggests it is the greater levels of stimulus found in urban areas that negatively affect helping behavior. In the survey context, House and Wolf (1978) conclude that population density accounts for some of the differences in trust and helping behavior found among urban and non-urban residents. Further, they find a modest but significant correlation between density and interview refusal rates.

Crime rates are also hypothesized to affect survey cooperation, albeit again indirectly. House and Wolf (1978) found that "rising crime rates, especially in urban areas, have been a major deterrent to willingness to be interviewed". They note that the perception of crime is the crucial mediator of individual bchavior, lcading to incrcased fcars of criminal victimization. Following this reasoning, higher crime rates lead to greater perceived threat, and hence reduced interactions with strangers (see also Iutcovich and Cox, 1990; Rucker, 1990). It is the perception of potential harm that induces sample persons to react negatively to survey requests. While the correlation between crime rates and fear of crime is not close to 1 (see Liska and Baccaglini, 1990), a number of studies have found fear of crime to be associated with actual victimization rates in various residential locations (e.g., Belyea and Zingraff, 1988; Lavrakas, 1982).

A final contextual factor often associated with urban life is that of social disorganization, characterized by weakened local kinship and friendship networks and reduced social participation in local affairs (see e.g., Fischer, 1982). It is argued that urban communities have a decreased capacity for social control (Sampson and Groves, 1989). The legitimacy of societal institutions, and the authority that such institutions may command over individuals, may be reduced in areas of low cohesion. In such areas, the relative lack of participation or involvement in the community may reduce the willingness to engage in activities (such as surveys) that are seen to benefit either that community or the society at large. 
A lack of social cohesion at the community level may have as its counterpart the isolation of individuals both from the local community and the society at large. This manifests itself not only in greater avoidance of interaction with and greater distrust of other members of the broader society, but also a diminished sense of obligation to act for the "social good". Indicators of a lack of social cohesion include transience of the population, large apartment complexes, racial/ethnic heterogeneity and physical decay of the neighborhood.

Of course, these contextual factors are all highly correlated. For example, Smith and Jarjoura (1989) report that population density and indicators of a lack of community social control (transience, heterogeneity, proportion of multi-family dwellings, etc.) are important correlates of criminal victimization (see also Covington and Taylor, 1991; Skogan and Maxfield, 1981). Goyder et al. (1992) combine many of these variables into a single indicator of social disorganization. We see these variables as complementary rather than competing alternative explanations for the effect of urbanicity on survey participation.

This paper is in part an extension of the work by House and Wolf (1978) and Goyder et al. (1992). House and Wolf found that much of the effect of urbanicity on refusal rates over time can be explained by differences in crime rates and population density. However, given the unit of analysis, they were unable to control for differences in socio-demographic characteristics of urban and rural residents. Such controls are at the heart of the debate over social environmental effects on interpersonal behavior. Classical theories of urbanism assert that urbanicity itself (characterized by large, diverse and concentrated populations) leads to social disorganization, isolation and lack of interpersonal trust (see Tittle and Stafford, 1992). In contrast, others argue that these effects are not due to the ecological charactcristics of citics per se, but rather to the fact that different types of people live in these different areas. It is thus important to control for differences in socio-demographic characteristics across settlement types (see Wilson, 1985; Fischer, 1973).

Goyder et al. (1992) undertook analyses similar to House and Wolf within a small number of urban areas ( 3 cities in Ontario, Canada). Using a personlevel analysis, they were able to control for a limited number of sociodemographic characteristics obtained from municipal assessment records. Although they found no effect of crime, density, or social disorganization on variation in response rates within a single metropolitan area (Toronto), they report that response rate differences between the three cities could be accounted for by city size and crime rate differences. Both these studies are thus limited; the first, by having no socio-demographic controls, and the 
second, by being restricted to a single geographical area. Our data allow us to overcome both these shortcomings. Nonetheless, our paper shares the weakness of both these studies in being unable to measure the social psychological effects of the environment, and we are forced to rely on indirect indicators of these concepts.

The goal of this paper is to examine the marginal effects of social environment factors on survey cooperation, controlling for key household-level correlates. We examine the contextual variables both without and with household-level controls. First, we model the effect of each of the social environment factors singly, without household-level controls, in order to validate the bivariate results found in the survey literature. Next we model the effect of each of these factors, controlling for appropriate householdlevel variables, to examine the marginal impacts of these contextual factors on cooperation rates. Finally, we combine a number of the key contextual variables in a model, both excluding and including household-level controls.

\section{Data collection design}

The 1990 U.S. decennial census provided us with a rare opportunity to obtain information on survey nonrespondents from their decennial census records. We matched all nonrespondent and a sample of respondent cases from each of the Consumer Expenditure Survey (Quarterly); the Current Population Survey; the National Health Interview Survey; the National Crime Survey; the National Household Survey on Drug Abuse; and the Survey of Census Participation.

From each of these surveys a probability sample of respondent and nonrespondent cases was selected. These cases were then matched to decennial census records at the household or address level (person-level information not being available for most nonrespondent cases). About 17,500 eligible sample cases (of which 7,000 were nonresponding households) were matched, with a match rate of $96.3 \%$. The analyses reported here are based on the cases successfully matched. In addition to household- and person-level data obtained from census records, aggregate block-level census data corresponding to each sample address were also obtained, to provide measures of the residential context of the sample household. For details of the survey-census match operation, see Groves and Couper (1993).

The surveys included in the match study have relatively high response rates (ranging from $82 \%$ to $97 \%$ ), making the detcetion of small effects on response rates difficult. The surveys cannot be considered representative of 
all household surveys conducted in the U.S., limiting generalizations to other surveys or organizations. The information we have on nonrespondent (and respondent) households is restricted to that collected in the decennial census, consisting only of kcy demographic indicators. Although many of the concepts outlined earlier are social psychological in nature, we possess in this study only demographic and socioeconomic attributes of households. This limits the range of analyses that can be performed in pursuit of an integrated theory. Nevertheless, the data allow us to examine correlates of nonresponse in a multivariate context, using data from six different surveys.

In this paper we have pooled the six surveys into a single dataset, containing only first-wave cases from panel surveys, leaving us with about 11,600 cases for analysis. The pooled dataset is weighted to account for differential probabilities of selection within each survey. Analyses performed on each of the six surveys separately produce essentially similar results to those from the pooled analyses.

\section{Analytic steps}

The analyses described here focus on refusals as one source of nonresponse. For our purposes, a cooperation rate is defined as: interviews/(interviews + refusals). Cooperation is thus defined as response, given contact, excluding "other noninterview" cases (e.g., those physically or mentally unable to respond). The multivariate modeling is done using logistic regression with a binary outcome variable coded as $1=$ interview, $0=$ refusal. Standard error estimates and statistical tests are calculated using Taylor Series approximation estimators, reflecting stratification, clustering, and probabilities of selection of the survey designs, using SUDAAN (Shah et al., 1993). The models used are fixed coefficient models, not random coefficient models. The variance estimates of the coefficients for the urbanicity variables, however, reflect the clustering of the samples into geographical areas (many of which are completely homogeneous on the urbanicity measures). The statistical tests thus reflect the inter-area component of variance.

The models include a number of household-level correlates of cooperation as controls. The household-level variables are motivated by a theoretical perspective and related empirical analyses described elsewhere (Groves and Couper, 1995a, 1995b). These include race/ethnicity of the reference person, single person household, housing structure (single unit, large multi-unit structures, other), presence of children in household, whether all persons in the household are under 30 , whether all are over 70 , whether the unit is owner occupied, and the monthly rent (for renters) and house value (for owners). 
In addition, a series of dummy variables for each of the surveys was included in all models to reflect differences in cooperation rates across surveys. For reasons of parsimony, the coefficients for these controls are omitted from the tables. Our focus here is on the effect of the social environment variables in the presence of these controls.

To these base models (containing survey indicators and household-level variables) was added a set of urbanicity indicators reflecting three categories of urbanicity: central city of a consolidated metropolitan statistical area (CMSA) (the largest 18 metropolitan areas of the U.S.), balance of the CMSA, and other areas (including both metropolitan statistical areas (MSA's) (containing cities of 50,000 or more and non-MSA's ("less urban areas")). Earlier analyses revealed no significant differences between these last two categories ("other urban" and "rural").

We use a county-level ${ }^{1}$ measure of serious crimes as an indicator of fear of crime. The measure used is the crime rate of the household's county of residence, as measured in 1988 by the FBI Uniform Crime Reports of incidents reported to the police. It would be preferable to have a measure of crime rates at lower spatial aggregation but none was available nationally. Crime rates are scaled to measure serious crimes per 1,000 population.

As an indicator of crowding, we use population density $(1,000$ 's of persons per square mile) measured at the city level. For sample cases in unincorporated areas, we use county-level density measures. As with crime rates, the density measure fails to reflect intracity variation in population density.

Without direct measures of social cohesion at the neighborhood or community level, we must again make use of indirect indicators. We argue that areas with a large percentage of persons residing in group quartcrs cxhibit a greater transience of the population, and hence reduced attachment to the community. Similarly, the larger the proportion of homes that are owneroccupied, the greater the permanence and commitment of residents to the neighborhood (see Sampson, 1988). Single-unit dwellings may also be associatcd with grcater cohesion, relative to multi-unit structures (and particularly high-rise apartment complexes) (see Smith and Jarjoura, 1989). Race diversity is another indicator of a lack of social cohesion. It is argued that greater racial diversity in a community reduces the cooperation among groups, and hence reduces social cohesion (see Miethe et al., 1991; Sampson and Groves, 1989). We use the percentage of persons of minority race as an indicator of race diversity. Finally, we argue that children act as catalysts for the involvement of parents in community-based activities (with schools often being the center of those activities). We thus use the proportion of children (and particularly those of school-going age) as a further indicator of social cohesion (see Lievesley, 1988). Wilson (1985) found that the presence of children in 
urban and suburban neighborhoods had a positive effect on perceptions of trust and helpfulness. The geographical-aggregate census data are limited to broad age categories, forcing us to use the percentage of persons under 20 as an indicator of the presence of children. All of these social cohesion indicators are measured at the level of the census block.

\section{Results}

The analytic plan for these data has the following goals: (a) to examine whether the data exhibit the same bivariate correlates of nonresponse found in the past literature; (b) for each of the single correlates, to examine whether their effects can be explained by household-level attributes; and (c) to estimate a model including all social environmental and household-level influences.

The first step of the analysis tests whether findings of social environmental differences in nonresponse common to the past literature apply to these data as well. Table 1 (column 1) contains the results of the logistic regressions of cooperation (response given contact) on each of the social environment factors singly. These models incorporate dummy variable indicators for each of the surveys to reflect differences in base cooperation rates across surveys. Only the logit coefficients for the social environment variables are presented. The likelihood ratio test (see Hosmer and Lemeshow, 1989) is also presented, for the significance of the social environment variables, relative to the base model with only dummy indicators for the different surveys.

The findings in Table 1 support those of House and Wolf (1978) and Goyder et al. (1992) with respect to urbanicity, population density and crime rates respectively. Residents of large metropolitan areas (and particularly the core cities of such areas), those in densely populated areas, and those in areas with high crime rates are less likely to accede to an interviewer's request to participate in a survey.

This is consistent with the literature that crowding, fear of crime and high levels of stimulus input associated with urban areas lead to avoidance of contact with strangers. This may be especially true of visits by interviewers to sample persons' homes or primary environments. The home as a primary environment gives individuals a measure of control over the number and type of people with whom they must interact and the number of social interruptions they are likely to experience (see Schiffenbauer, 1979). Intrusions into such primary environments may be particularly threatening for those in high crime, high density urban areas that may provide little opportunity to retreat from such intrusions elsewhere. In addition, there is anec- 
Table 1. Effect of social environment variables on cooperation, with and without householdlevel controls

\begin{tabular}{|c|c|c|}
\hline & $\begin{array}{l}\text { Excluding household } \\
\text { controls }\end{array}$ & $\begin{array}{l}\text { Including household } \\
\text { controls }\end{array}$ \\
\hline Social environment variables & $\begin{array}{l}\text { Coefficient } \\
\text { (standard error) }\end{array}$ & $\begin{array}{l}\text { Coefficient } \\
\text { (standard error) }\end{array}$ \\
\hline \multicolumn{3}{|l|}{ 1. Urbanicity: } \\
\hline Central city & $\begin{array}{l}-0.56^{* *} \\
(0.12)\end{array}$ & $\begin{array}{l}-0.50^{* *} \\
(0.14)\end{array}$ \\
\hline Balance of CMSA & $\begin{array}{l}-0.35^{* *} \\
(0.11)\end{array}$ & $\begin{array}{l}-0.20 \\
(0.14)\end{array}$ \\
\hline Likelihood ratio test: & $G=26.64 * *$ & $G=12.76^{* *}$ \\
\hline \multicolumn{3}{|l|}{ 2. Population Density: } \\
\hline Persons per square mile (in thousands) & $\begin{array}{r}-0.041^{* *} \\
(0.0083)\end{array}$ & $\begin{array}{l}-0.037^{* *} \\
(0.010)\end{array}$ \\
\hline Likelihood ratio test: & $G=34.65^{* *}$ & $G=19.29 * *$ \\
\hline \multicolumn{3}{|l|}{ 3. Crime Rate: } \\
\hline Serious crimes per 1,000 population & $\begin{array}{l}-0.041^{* *} \\
(0.015)\end{array}$ & $\begin{array}{c}-0.037^{*} \\
(0.018)\end{array}$ \\
\hline Likelihood ratio test: & $G=37.25 *$ & $G=24.24^{* *}$ \\
\hline \multicolumn{3}{|l|}{ 4. Social Isolation Indicators: } \\
\hline Percent persons in group quarters & $\begin{array}{c}0.010 \\
(0.011)\end{array}$ & $\begin{array}{c}0.013 \\
(0.013)\end{array}$ \\
\hline Percent homes owner occupied & $\begin{array}{r}0.00037 \\
(0.0019)\end{array}$ & $\begin{array}{r}0.0011) \\
(0.0029)\end{array}$ \\
\hline Percent persons of minority race & $\begin{array}{c}-0.00090 \\
(0.0015)\end{array}$ & $\begin{array}{c}-0.0047 \\
(0.0024)\end{array}$ \\
\hline Percent single detached units & $\begin{array}{c}-0.00049 \\
(0.0016)\end{array}$ & $\begin{array}{l}-0.0020 \\
(0.0020)\end{array}$ \\
\hline Percent persons under 20 years old & $\begin{array}{r}0.016^{* *} \\
(0.0044)\end{array}$ & $\begin{array}{c}0.011^{*} \\
(0.0052)\end{array}$ \\
\hline Likelihood ratio test: & $G=24.91 * *$ & $G=14.53 *$ \\
\hline
\end{tabular}

$* p<0.05$.

${ }^{* *} p<0.01$.

dotal evidence that concerns about personal safety on the part of interviewers may alter their persuasion behavior in such neighborhoods, leading to their greater acceptance of reluctance to participate.

It is noteworthy that population density and crime rates appear to have greater predictive power than the urbanicity indicators themselves (as judged by the model fit statistics). Most surveys can provide comparisons of response rates in urban versus rural areas, and almost uniformly, it is found that lower rates apply in urban areas. The more powerful predictive value of population density and crime rates may suggest that thosc attributes of urban areas underlie the lower urban participation rates. 
Table 1 also present coefficients for measures that might be considered indicators of social cohesion, entered together in the final model in the first column of Table 1. These variables as a group explain measurable amounts of variation in rates of cooperation $(G=24.91$, $\mathrm{df}=5, p<0.01)$. However, few of the predictors individually reach traditional levels of statistical significance. The single exception is the percentage of persons under 20 , which has a positive effect on survey cooperation. This supports the findings of Lievesley (1988), for survey cooperation, and Wilson (1985), in terms of trust and helping behavior among younger households.

At this point in the analysis, most of the speculations and findings from the past literature have been supported with these data. Despite the fact that the six surveys have higher overall cooperation rates than do most of the surveys studied in the past literature, the sets of social environmental correlates are largely similar.

The next step in the analysis has not been possible in most past studies a test of whether the social environmental correlates reflect spurious relationships, that urban areas have lower cooperation rates merely because they disproportionately contain types of people who tend to refuse participation, regardless of where they live. We address this possibility by adding to the models, household-level control variables found useful in predicting participation in other analyses (see Couper and Groves, 1996).

Column 2 of Table 1 presents the coefficients for the social environment variables, controlling on both the survey indicators and the set of householdlevel variables. Comparing these coefficients with those in the first column, it can be seen that urbanicity, population density, crime rate, and the percentage of persons under 20 years old all still have significant marginal effects on survey cooperation, even after controlling for household-level correlates. However, as expected, the size of each of the individual coefficicnts has becn reduced. The coefficient most affected is that for the contrast of the suburbs of the CMSA's. It appears that much of their lower cooperation rate is explained by household-level factors (a movement of -0.35 to -0.20 in the size of the coefficient). Nonetheless, the basic finding is that most of the environmental effects found on the single predictor level survive controls for household-level attributes.

The final step in the analysis examines whether the combined effects of social environmental and household-level variables are consistent with the theoretical propositions above. Two multivariate combinations of predictors are explored.

The first addresses the question of whether the inference using singlepredictor models of social environmental effects would change when multiple predictors are examined jointly. For example, we know that the central cities 
Table 2. Reduced social environment model, excluding and including household-level controls

\begin{tabular}{lll}
\hline & $\begin{array}{l}\text { Excluding household } \\
\text { controls }\end{array}$ & $\begin{array}{l}\text { Including household } \\
\text { controls }\end{array}$ \\
\cline { 2 - 3 } Social environment variables & $\begin{array}{l}\text { Coefficient } \\
\text { (standard error) }\end{array}$ & $\begin{array}{l}\text { Coefficient } \\
\text { (standard error) }\end{array}$ \\
\hline Central city & $-0.31^{*}$ & -0.29 \\
Balance of CMSA & $(0.15)$ & $(0.17)$ \\
Population density & $-0.23^{*}$ & -0.12 \\
Crime rate & $(0.11)$ & $(0.14)$ \\
& $-0.021^{*}$ & -0.022 \\
Percent persons under 20 years old & $(0.010)$ & $(0.012)$ \\
& -0.011 & -0.016 \\
Likelihood ratio test for social & $(0.017)$ & $(0.019)$ \\
environment variables: & $0.012^{* *}$ & 0.0066 \\
\hline
\end{tabular}

$* p<0.05$.

** $p<0.01$.

have higher crime rates $(r=0.56)$. Does the lower cooperation rates of the central cities merely reflect the higher crime rates of those areas? Such questions are addressed in the first model in Table 2. It can be seen that including all the social environment variables in a single model (controlling for survey design differences only) reduces the strength of each coefficient relative to its size in the models in Table 1.

The largest reductions in size of effect appear for the crime rate variable (a reduction from -0.041 to -0.011 ). From other analyses we know that this is largely the effect of controls on population densily and urbanicity. This is consistent with the notion that the anonymity and reluctance to interact with strangers, common to densely populated urban areas, is sufficient for reduced survey cooperation, and that the influence of crime rates on reluctance is marginally insignificant. (We remind ourselves that another interpretation is the fact that the crime rate indicator may be measured at the wrong level to observe effects.)

The model that combines all social environmental effects also shows reduced effects of the urbanicity indicators. This shows that among situations that have similar crime rates and population density, the contrasts of central city, suburb, and other locales are not as important. However, the direction of the urbanicity effects are still those found in the simpler models.

Finally, the variable least affected by the presence of other social environmental variables is "percent of persons under 20 years of age", a proxy for 
the density of families with children in the immediate area of the sample household. Such neighborhoods show strong tendencies toward cooperation with the survey requests, wherever they are located, whatever the density and crime rates.

The final step in the analysis is to examine all the social environmental predictors in the presence of the household-level control variables. With that analysis we again compare the values of the coefficients for each of the social environmental variables and their marginal effect on the overall predictive value of the model.

The second model in Table 2 shows that none of the social environmental variable coefficients remain statistically significant at traditional levels when controlling for household-level variables. Such controls have the largest impact on the coefficient for the "percent of persons under 20 years old" (from 0.012 to 0.0066 ). This is not unexpected either statistically or theoretically. The Lievesley (1988) hypothesis on this attribute is that young families with children tend to grant interviews, and the household variables contain two measures, whether the household has children and whether all persons in the household are less than 30 years old. In the presence of these household attributes, the social environmental measure of whether there are young persons in the neighborhood is a less important predictor. The data support the original theoretical proposition; the locus of its effects are the household, rather than the neighborhood. In short, it's more important that the household is a young family with children than that the household is located in a neighborhood with young families with children.

Controls on the household-level variables also reduce the importance of the urbanicity indicators, especially the indicator for suburbs of CMSA's (from -0.23 to -0.12 ). This was suggested in the model in Table 1 (second column), and reflects the fact that the type of households that live in these areas are from socio-demographic groups that tend not to cooperate with surveys, no matter where they live.

The environmental predictors least affected by the household-levcl controls are population density and the dummy variable for the central cities of the CMSA's. Both of these variables have coefficients with magnitudes similar to those before the household controls and with standard errors quite close to traditional levels of statistical significance.

Finally, we note that attention to individual coefficients in the full model in Table 2 may mislead. It is true that no single coefficient for the social environmental variables achieves traditional levels of statistical significance. It does not imply, however, that different social environments are similar on their rates of cooperation, controlling on household attributes. The social environmental variables as a group do significantly improve the fit of the 
overall model $(G=38.25, \mathrm{df}=4, p<0.01)$ after household-level effects are accounted for. The importance of individual environmental variables, however, is diminished. One way to summarize this crudely is to compare the decrease in the two likelihood ratio statistics associated with the social environmental variables, one without the household-level controls, and one with the household controls. The reduction is from 70.21 without the household controls, to 38.25 with the controls. In short, about (70.21-38.25)/70.21 or 46 percent of the explanatory power of the social environmental variables is due in some sense to household-level differences across social environments.

\section{Conclusions and discussion}

Large urban areas in the United States are often densely populated, often with high crime rates, and sometimes with weakened community ties among their residents. These areas tend also to be populated by single adult households, large multi-unit structures and high proportions of renters. All of the attributes singly are related to lower cooperation with surveys, but also with reduced helpfulness and prosocial behavior in general. Thus, what to survey researchers forms a limitation on statistical inference is more generally a powerful force affecting everyday behaviors of urban dwellers.

This paper examined an important question - whether the components of environmental effects could be separately identified and whether the components remain influential when the personal attributes of residents are taken into account.

With a dataset from six different national surveys covering a large number of geographical areas, we replicate prior findings that large urban areas, dense populations, and areas with high crime rates exhibited lower cooperation on the surveys. We find only modest impact of the indicators of social cohesion on cooperation. Independent effects of the urbanicity, density, and crime rates are measurable. The fact that these three variables are so highly correlated produces the large differences between urban and rural areas in survey response rates.

Adding a set of household-level controls reduces the strength of the social environment effects, but does not eliminate them entirely. About half of the effect of the social environmental variables arises because of differences in household structure, race, age of household members, presence of children, and socioeconomic attributes of households. That a large portion of the environmental differences in response rates is explained by household-level attributes is important in locating the causes of survey participation. In a 
practical sense this means that survey administrators should go below the level of sample areas in assessing the likely cooperation rates in a survey, to subclasses within urban areas, for example, that will have behaviors not dissimilar to members of the same subclass in other areas. From a theoretical perspective, the finding reminds us that a theory of survey participation will be likely to have its powerful effects at the person or household-level, not at higher ecological levels.

On the other hand, the result that much of the lower cooperation among residents of large urban, high density, high crime areas remains unexplained by household-level attributes underscores the fact that the data do not identify all the household-level attributes leading to the decision to accept or refuse a survey request. These areas do appear to foster behaviors unlike those in other areas. We believe, along with much of the past literature on crowding and urbanicity effects on social interaction, that the missing variables are a set of social psychological attributes. For example, we would hypothesize that measures of fear of crime at the household level would explain away much of the effect of crime rates. In the absence of these and other such variables, however, we must speculate on the social psychological influences on survey participation.

It is important to remember that the social cohesion indicators (with one exception) do not perform as expected. One possibility is that they are weaker indicators of the underlying concepts than the other social environment variables. The links between crime rates and fear of victimization, and between population density and avoidance of contact with strangers, may be stronger than those for the indicators of social cohesion available to us. The impact of community cohesion in shaping the context in which the request for survey cooperation takes place merits further exploration.

\section{Acknowledgements}

The research described here is supported by a funding consortium of the U.S. Bureau of the Census, Bureau of Justice Statistics, Bureau of Labor Statistics, Bureau of the Census, National Center for Health Statistics and the Substance Abuse and Mental Health Services Administration. Contents of the paper are the responsibility of the authors and do not necessarily represent those of the above agencies. The contributions of Larry Altmayer and Antoinette Tremblay to the analyses of these data are gratefully acknowledged. 


\section{Note}

1. Counties are sub-state administrative units, of which there are about 3,100 in the U.S.

\section{References}

Baum, A. \& Valins, S. (1979). Architectural mediation of residential density and control: Crowding and the regulation of social contact, in L. Berkowitz (ed.), Advances in Experimental Psychology, Volume 12, New York: Academic Press, pp. 31-175.

Belyea, M. \& Zingraff, M.T. (1988), Fear of crime and residential location, Rural Sociology, 53: $475-486$.

Brehm, J. (1993). The Phantom Respondents; Opinion Surveys and Political Representation. Ann Arbor: University of Michigan Press.

Couper, M.P. \& Groves, R.M. (1996). Household-level determinants of survey nonresponse, in M. Braverman (ed.), Advances in Survey Research. New Directions for Evaluation. San Francisco: Jossey-Bass, forthcoming.

Covington, J. \& Taylor, R.B. (1991). Fear of crime in urban residential neighborhoods: Implications of between- and within-neighborhood sources for current models, Sociological Quarterly, 32: 231-249.

Fischer, C. (1973). On urban alienation and anomie: Powerlessness and social isolation, American Sociological Review, 38: 311-326.

Fischer, C. (1982). To Dwell Among Friends: Personal Networks in Town and City, Chicago: University of Chicago Press.

Franck, K.A. (1980). Friends and strangers: The social experience of living in urban and nonurban settings, Journal of Social Issues, 36: 52-71.

Goyder, J. (1987). The Silent Minority; Nonrespondents on Sample Surveys, Boulder, CO: Westview Press.

Goyder, J., Lock, J. \& McNair, T. (1992). Urbanization effects on survey nonresponse: A test within and across cities, Quality \& Quantity, 26: 39-48.

Groves, R.M. (1989). Survey Errors and Survey Costs, New York: Wiley.

Groves, R.M., Cialdini, R.B., \& Couper, M.P. (1992). Understanding the decision to participate in a survey, Public Opinion Quarterly, 56: 475-495.

Groves, R.M. \& Couper, M.P. (1992). Respondent-interviewer interactions in survey introductions. Paper presented at the Third International Workshop on Household Survey Nonresponse, The Hague, September.

Groves, R.M. \& Couper, M.P. (1993). Unit nonresponse in demographic survcys, Proceedings of the Bureau of the Census Annual Research Conference, Washington: Bureau of the Census, pp. 593-619.

Groves, R.M. \& Couper, M.P. (1995a). Theoretical motivation for post-survey nonresponse adjustment in household surveys, Journal of Official Statistics, 11: 93-106.

Groves, R.M. \& Couper, M.P. (1995b). Contact-level influences on cooperation in face-to-face surveys, Journal of Official Statistics, forthcoming.

Hosmer, D.W. \& Lemeshow, S. (1989). Applied Logistic Regression, New York: Wiley.

House, J.S. \& Wolf, S. (1978). Effects of urban residence on interpersonal trust and helping behavior, Journal of Personality and Social Psychology, 36: 1029-1043.

Iutcovich, J.M. \& Cox, H. (1990). Fear of crime among the elderly - is it justified? Journal of Applied Sociology, 7: 63-76.

Kalton, G. (1983). Compensating for Missing Survey Data, Ann Arbor: Institute for Social Research, University of Michigan.

Korte, C., Ypma, I., \& Toppen, A. (1975). Helpfulness in Dutch society as a function of 
urbanization and environmental input level, Journal of Personality and Social Psychology, 32: 996-1003.

Lavrakas, P.J. (1982). Fear of crime and behavioral restrictions in urban and suburban neighborhoods, Population and Environment, 5: 242-264.

Levine, R.V., Martinez, T.S., Brase, G., \& Sorenson, K. (1994). Helping in 36 U.S. cities, Journal of Personality and Social Psychology, 67: 69-82.

Lievesley, D. (1988). Unit Non-Response in Interview Surveys, London: Social and Community Planning Research (unpublished working paper).

Liska, A.E. \& Baccaglini, W. (1990). Feeling safe by comparison: Crime in the newspapers, Social Problems, 37: 360-374.

McCarthy, D.P. \& Saegert, S. (1979). Residential density, social overload, and social withdrawal, in J.R. Aiello \& A. Baum (eds.), Residential Crowding and Design, New York: Plenum Press, pp. 55-57.

Miethe, T.D., Hughes, M. \& McDowall, D. (1991). Social change and crime rates: An evaluation of alternative theoretical approaches, Social Forces, 70: 165-185.

Milgram, S. (1970). The experience of living in cities, Science, 67: 1461-1468.

Rucker, R.E. (1990). Urban crime: Fear of victimization and perceptions of risk, Free Inquiry in Creative Suciology, 18: 151-160.

Sampson, R.J. (1988). Local friendship ties and community attachment in mass society: A multilevel systemic approach, American Sociological Review, 53: 766-779.

Sampson, R.J. \& Groves, W.B. (1989). Community structure and crime: Testing social-disorganization theory, American Journal of Sociology, 94: 774-802.

Schiffenbauer, A. (1979). Designing for high-density living, in J. R. Aiello \& A. Baum (eds.), Residential Crowding and Design, New York: Plenum Press, pp. 229-240.

Shah, B.V., Barnwell, B.G., Hunt, P.N., \& LaVange, L.M. (1993). SUDAAN User's Manual, Release 6.34, Research Triangle Park, NC: Research Triangle Institute.

Skogan, W.G. \& Maxfield, M.G. (1981). Coping with Crime: Individual and Neighborhood Reactions, Beverly Hills: Sage.

Smith, D.A. \& Jarjoura, G.R. (1989). Household characteristics, neighborhood composition and victimization risk, Social Forces, 68: 621-640.

Smith, T.W. (1983). The hidden 25 percent: An analysis of nonresponse on the 1980 General Social Survey, Public Opinion Quarterly, 47: 386-404.

Steblay, N.M. (1987). Helping behavior in rural and urban environments: A meta-analysis, Psychological Bulletin, 102: 346-356.

Steeh, C.G. (1981). Trends in nonresponse rates, 1952-1979, Public Opinion Quarterly, 45: 4057.

Stokols, D. (1976). The expcricnce of crowding in primary and sccondary cnvironments, Environment and Behavior, 8: 49-86.

Tittle, C.R. \& Stafford, M.C. (1992). Urban theory, urbanism and suburban residence, Social Forces, 70: 725-744.

Wilson, T.C. (1985). Settlement type and interpersonal estrangement: A test of the theories of Wirth and Gans, Social Forces, 64: 139-150. 